Research report

\title{
Out of our heads: Addiction and psychiatric externalism
}

\author{
Shane N. Glackin *, Tom Roberts, Joel Krueger \\ Department of Sociology, Philosophy, and Anthropology, University of Exeter, UK
}

\section{A R T I C L E I N F O}

\section{Keywords:}

4E cognition

Addiction

Extended mind

Integrative framework

Psychiatric externalism

Recovery

\begin{abstract}
A B S T R A C T
In addiction, apparently causally significant phenomena occur at a huge number of levels; addiction is affected by biomedical, neurological, pharmacological, clinical, social, and politico-legal factors, among many others. In such a complex, multifaceted field of inquiry, it seems very unlikely that all the many layers of explanation will prove amenable to any simple or straightforward, reductive analysis; if we are to unify the many different sciences of addiction while respecting their causal autonomy, then, what we are likely to need is an integrative framework. In this paper, we propose the theory of "Externalist" or "4E" - for extended, embodied, embedded, and enactive - cognition, which focuses on the empirical and conceptual centrality of the wider extra-neural environment to cognitive and mental processes, as a candidate for such a framework. We begin in Section 2 by outlining how such a perspective might apply to psychiatry more generally, before turning to some of the ways it can illuminate addiction in particular: Section 3 points to a way of dissolving the classic dichotomy between the "choice model" and "disease model" in the addiction literature; Section 4 shows how 4E concepts can clarify the interplay between the addict's brain and her environment; and Section 5 considers how these insights help to explain the success of some recovery strategies, and may help to inform the development of new ones.
\end{abstract}

\section{Introduction}

One of the most perplexing features of addiction, from an academic point of view, is the sheer number of levels at which apparently causally significant phenomena occur. As a subject, it seems to be simultaneously affected by biomedical, neurological, pharmacological, clinical, social, and politico-legal factors, among many others. This sort of problem - the analysis of the way that different vocabularies and methodologies, ostensibly concerned with the same subject, are related - has long been a central preoccupation of analytic philosophers ([1], ch.1). In such a complex, multifaceted field of inquiry, it seems very unlikely that all the many layers of explanation will prove amenable to any simple or straightforward, reductive analysis; nobody thinks that a comprehensive account of addiction will amount to "neurochemistry and stamp-collecting". ${ }^{1}$ If we are to unify the many different sciences of addiction while respecting their causal autonomy, then, what we are likely to need is an integrative framework. ${ }^{2}$

In this paper, we propose a candidate for such a framework, which has been much discussed in recent years in the philosophy of mind and, increasingly, the philosophy of psychiatry. This is commonly known as "Externalist" or "4E" - for extended, embodied, embedded, and enactive - cognition, and focuses on the empirical and conceptual centrality of the wider extra-neural environment to cognitive and mental processes. We begin in Section 2 by outlining how such a perspective might apply to psychiatry more generally, before turning to some of the ways it can illuminate addiction in particular: Section 3 points to a way of dissolving the classic dichotomy between the "choice model" and "disease model" in the addiction literature; Section 4 shows how $4 \mathrm{E}$ concepts can clarify the interplay between the addict's brain and her environment; and Section 5 considers how these insights help to explain the success of some recovery strategies, and may help to inform the development of new ones. We do not aim to provide novel findings here, nor to overturn

\footnotetext{
* Corresponding author.

E-mail address: s.n.glackin@exeter.ac.uk (S.N. Glackin).

${ }^{1}$ In a classic expression of reductionism, Sir Ernest Rutherford is reported to have quipped that "all science is physics or stamp-collecting"; either the investigation of fundamental phenomena, or the mere cataloguing and curating of the exotic local phenomena which resulted.

${ }^{2}$ De Haan [101] outlines a notably similar project, though differing in two important respects. The target of her integrative ambition is much broader (psychiatry as a whole), while her framework itself is narrower, involving just one of the four "E"s we employ, enactivism. "(A)n overarching framework," as she explains, "provides orientation, treatment rationale, a shared language for communication with all those involved, and the means to explain treatment decisions to health insurers and to society at large" (p.3).
} 
the claims advanced within the various sciences of addiction; rather, we wish to develop a common footing for those various disciplines, allowing them to communicate better amongst themselves on the basis of claims they already find uncontroversial.

\section{Externalist psychiatry}

Where do we have to look in order to understand a person's mental health? A historically popular response is inside their head, in their brain. But following recent trends in the philosophical study of the mind, an increasingly large literature has suggested that the health and illness of the mind, too, may be more widely constituted (e.g., [2-15]). Take the case of schizophrenia. One sort of question we can ask is about the constitution of schizophrenia; what is the physical or material basis of such a condition? We might locate the answer to this question in the brain, but we might also look more widely — for example, to work suggesting that core self-disturbances in schizophrenia are (at least partially) constituted by disturbances of the individual's embodied relationship with others and their material environment more generally $[8,16]$. A second sort of question about schizophrenia concerns status; in respect of what criteria is it the case that some individual does or does not suffer from schizophrenia? Again, an answer to this question might appeal only to neural properties, or it might appeal to a much broader set of social, ecological, or epidemiological considerations, for instance [17].

Thus, against the traditional biomedical model of mental health and illness [18]; c.f. [19-23] - which holds that psychiatric phenomena are determined by facts about the brain, and that we should therefore expect to explain mental illness exclusively in terms of neural activity - we propose an externalist model. This holds that a person's mental health order, or disorder - can depend upon facts about her social, material, and cultural environment, and not just upon facts about her brain. But this claim can mean a variety of different things; for instance, externalist answers to the status question will often look less radical than externalist answers to the constitution question. One thing, therefore, that we are concerned to do as externalists is to provide a "taxonomy" of different forms of externalism about mental disorder.

For example, suppose that we say mental illness depends upon society. One thing that could be meant by this is that mental illness tends to flourish in, or may even be caused to do so by, the social environment; thus, social conditions in schools or prisons might be depressogenic. Another thing we might mean is that mental illness is simply a "social construct", lacking any real physical basis. ${ }^{3}$ This was the anti-realist view held by Thomas Szasz (e.g. [24], [25]), who held that illness required the presence of lesions, and so that "mental illness" was a myth used to discredit behaviour of which we disapproved, or which we found in various ways disgusting, inconvenient, or undesirable; brains could have lesions, and so illnesses, but minds could not. Thirdly, we might mean that whether somebody is mentally ill depends on her relation to other members of her population; possessing an anxiety disorder, for instance, might simply mean that she experiences anxiety significantly more frequently than other members of her community or other reference class (e.g. [26,27]). This would be an externalist answer to the status question that remains neutral on how best to answer the constitution question. And fourthly, by analogy with the "institutional theory of art" (e.g. [28]), which holds that something is a work of art just in case a community of art experts says that it is, we might mean that whether a person has a mental illness or not is just a matter of whether she is judged by consensus among the psychiatric profession to do so. And this is just to scratch the surface of the possibilities.

This externalist perspective builds from a more general philosophical view of the mind, sometimes referred to as " $4 \mathrm{E}$ " cognition. This view

\footnotetext{
3 Though see [102] for an argument against the idea that social constructivism about any disease implies that it lacks a real physical substrate.
}

regards the mind as being essentially embodied (meaning that a creature's mental life is structured and governed by her physiological makeup as well as her neurological properties); embedded (mental states and processes unfold within a particular environmental niche, composed in part of an assortment of material and informational scaffolding, which supports and enhances cognitive powers); enacted (thinking beings inhabit a concerned perspective, so that through their interactions with their ecological surroundings they thereby create and discover meaning for themselves); and/or extended (the material underpinnings of an individual's psychological states and processes are not confined to that individual's head, or other biological boundaries, but can include resources physically located in the wider environment). These four different features can come apart; each can be manifested independently of the others. And they differ in degrees of radicalism too, as we shall see.

In short, on the externalist perspective, a person's mental life is seen as shaped, structured, enriched, supported, and scaffolded by her body, and by the social, material, and cultural environment in which she is housed. We should not, therefore, expect to understand the mind and its disorders just by looking at the brain in isolation from the rest of the body, or from the complex social and material environment that we as humans build for ourselves. Our psychological life - our thinking, reasoning, remembering, emotions, experiences - is deeply embedded in the world around us, a world full of informational resources, tools, artefacts, computers, diaries, smart-phones, other people, social conventions, rules, and so forth. In its strongest versions, this view suggests that mental states may not merely interact with, but be themselves composed by, such resources, and therefore be physically distributed across the brain, the body, and the outside world (e.g. [29]).

Externalist psychiatry therefore asks how these 4E ways of thinking might inform our understanding of mental health and disorder. ${ }^{4}$ For instance, how - if at all - are symptoms of depression shaped and structured by one's interactions with other people [30-32]? Is autistic spectrum disorder embodied and situated, or is it "purely neural" [13, 33-35]? It also asks how the various approaches explored in this section, all of which promote in different ways - and to different degrees of radicalism - the idea that understanding mental health and illness requires a focus that goes beyond the brain, fit together. In the following section we begin to explore how externalist psychiatry, in its many forms, might apply to, and inform, the integrated and multidisciplinary study of addiction.

\section{Beyond choice and disease}

At first glance, addiction seems to fit the 4E perspective extremely neatly. It is embodied insofar as the addict's physiological properties (e.g. cravings felt within her body, and experienced as world-directed drives to use her body to alleviate bodily discomfort) structure and govern her mental life. It is embedded insofar as her mental activities both unfold within and depend upon her ecological niche; patterns of addiction, and of characteristic behaviour by addicts, are clearly influenced by the social and legal environment, for instance. It is enacted insofar as the addict's mental activities occupy a concerned perspective that imbues her environment with subjective meaning; she experiences the environment in particular ways, attributing to aspects of it a significance which others don't, and lending particular buildings, shops, street

\footnotetext{
${ }^{4}$ Externalist psychiatry in this way challenges views according to which psychiatric disorders are a matter of one or more functional neurological failures. Some recent examples can be found in characterizations of depression [103-105] and anxiety [106] as brain disorders. Similarly, Insel and Quirion [107] begin their general defense of psychiatry as a clinical neuroscience discipline by insisting that "mental disorders be understood and treated as brain disorders" (p. 2221). And as we discuss below, many theorists regard addiction simple as a disease of the brain (e.g. [43]; [45]).
} 
corners, or support communities a salience which is not "independently" or "objectively" there, but rather depends on and is constituted by her and other addicts' needs and desires. And finally, it may also be extended where her psychological states are underpinned by resources physically external to her body. We will explore this point in more detail later, but such things as possessing legal vendors, a stash, or - in the notorious case of George Jones - a ride-on lawnmower one can use to reach a bar several miles away, may be important environmental constituents of the addict's peace of mind, and may therefore be essential to other aspects of her cognitive functioning. Or, we might look to work on social media addiction, which acknowledges the increasingly-central role the Internet and online spaces play in scaffolding synchronic and diachronic features of our affective life [36]. In these cases, individuals are integrated with a rich array of ready-to-hand environmental resources, such as smartphones and social media spaces, that are designed specifically to maintain user attention and drive engagement; they may set up an ongoing feedback loop that persistently nudges users toward addictive practices and scaffold patterns of negative affect regulation (depression; rumination; low self-esteem, etc.) [37-39].

If anything, these observations may seem trivial: doesn't everyone believe that a person's mental life is supported and enriched by the environment in which they are housed? We want to make the case here that they are more than a mere collection of platitudes; after all, externalism is quite a radical and controversial position in the philosophy of psychiatry, and philosophy of mind. One way we might hope to do that would be to provide substantive new insights into addiction based on $4 \mathrm{E}$ thinking, though that is not what we will offer in this paper. Rather, and in keeping with the theme of the Special Issue, we will seek to show that it can provide an integrated theoretical framework, organising and explaining together a wide variety of existing perspectives and practices.

One notable area in which externalism might perform this kind of integrative role is the classic dichotomy in the literature between the "Disease Model" and the "Choice Model" of addiction [40,41]. Caricaturing somewhat, we can say that theorists following the Disease Model tended to treat addiction as neurally-based, all-or-nothing (one is either an addict, or one is not), uncontrollable, progressive, and requiring treatment if it is not to result in eventual death (e.g. [42-46]); whereas adherents of the Choice Model viewed addiction as affecting, but not being reducible to, the brain chemistry, as coming in degrees, as often being attributable to social and environmental factors, but as fundamentally concerning decisions for which the addict is personally responsible (e.g. [3,47-50]). However, most theorists - including, it should be stressed, several of those cited as examples - now reject these rather simplistic caricatures. But the dichotomy between them still influences the framing of the literature, with the classic "Disease Model" and "Choice Model" presented as "extremes", or poles, of the conceptual space. More sophisticated and nuanced positions are therefore depicted as occupying the "moderate" middle ground between them. The $4 \mathrm{E}$ perspective, however, can help us to move beyond the dichotomy by explaining what is wrong with posing the debate in these terms in the first place.

Between the 4E perspective and the Choice Model, there appears to be a clear affinity; the Choice Model posits a range of social and environmental factors which can influence both the initial etiology and the course, development, and prognosis of addiction. External factors thus seem to be centrally involved in the basic characteristic functioning of the addicted person, and the addicted mind. And there can scarcely be a more familiar observation in the empirical literature; from the classic "Rat Park" studies of Bruce Alexander onwards [51,52]; (cf. [53,54]), which showed that even cocaine-addicted rats would cease choosing to consume cocaine once more stimulating alternative activities - like play, socialising, or consuming saccharine - were provided, it has been clear that a key variable factor determining addiction rates has been the availability of alternatives in the environment. In a much-cited case, the Vietnam war saw extremely high rates of heroin use among G.I.s, the great majority of whom stopped without difficulty upon their discharge and return the USA.; of those who did not, comorbidity with PTSD and other psychiatric conditions was almost universal, with opiate use posited as a form of self-medication (e.g. [55,56]; [66]; [57]).

The Disease Model is slightly trickier to reconcile with the $4 \mathrm{E}$ perspective, though the process of working out how to do so is instructive. What externalist approaches to psychiatry suggest is that social and environmental factors are standardly implicated in mental illness. Will Davies [3], for instance, points out that disorders like PTSD and reactive detachment disorder "constitutively require" external triggers - whatever the brain state is, a psychiatric case is not PTSD unless it takes place following trauma - while major depression requires disproportionate response to external stimulus, and other conditions such as oppositional defiant disorder, avoidant personality disorder, selective mutism, and factitious disorder are all inherently social in their presentation. So, a purely neural basis is not a necessary condition of psychiatric disease.

Tellingly, Davies also cites Neil Levy's [58] paper, "Addiction is not a brain disease (and it matters)" in this regard; if you inhabit a world in which cocaine does not exist, Levy argues, then it doesn't matter what neuropharmacological state you find yourself in there, you cannot be a cocaine addict. Nor are the rest of us, with dispositions to react in characteristically addictive ways to a nearly infinite variety of potential but non-existent toxins, thereby the sufferers of multiple addictions. The key insight here is in Levy's title, though we can't say if it was his intention; addiction is not a brain disease, but it does not follow that it is not a disease at all. Very little, on an externalist view of psychiatry, is just a brain disease; psychiatric illness is not confined to the inside of the skull.

So, the 4E theorist will here propose a better version of the Disease Model, a "Disease Model 2.0". Of course, the correct definition of "disease" is widely disputed among philosophers, and the debates over addiction's disease-status have only rarely engaged with this literature ([59], p. 44). But our suggestions here align with several recent moves in that literature, and so can be motivated independently of their utility in moving this particular debate forward (even if we cannot provide a full-dress defense of those moves at this point).

On this improved model, the neural basis of addiction is first of all replaced with a view of addiction as simultaneously neurally-andexternally constituted. This follows not only Davies' claims as already summarised ( $c f$. also $[2,7,14,15])$, but also Glackin's [6] arguments that many somatic or bodily diseases, too, are externally constituted in the same or analogous ways; the concept of "disease" generally - and not only psychiatric disease - therefore includes social and environmental factors not merely as causes, but frequently as necessary constituents of the condition. And other theorists have advanced self-consciously "holistic" views of health and illness (e.g. [60-63]), ${ }^{5}$ which have nevertheless sought to incorporate the main insights of the classic "biomedical" accounts associated with Boorse [26,27] and Wakefield $[64,65]$. In short, as far as the current literature on disease goes, those who view addiction as a disease should not on that ground object to this modification.

With this feature of the Disease Model amended, though, we can see grounds for similarly relaxing or qualifying most of the other stances which divide its adherents from those of the Choice Model. With perhaps

\footnotetext{
${ }^{5}$ In fact, in modern discussion the point goes back at least to John Dewey, who told the College of Physicians at St. Louis that "(w)e must observe and understand internal processes and their interactions from the standpoint of their interactions with what is going on outside the skin" ([108], p. 326); [109], p. 27) invokes this speech in support of de Haan's proposed [101] enactivist psychiatry.
} 
the exception of Thomas Szasz (e.g. [24,25]), very few philosophers of disease have viewed it as possessing determinate, all-or-nothing criteria. ${ }^{6}$ So again, viewing addiction as a disease does not entail treating it as a binary condition, that one either has or does not have, with no liminal or intermediate cases. Moreover, once we admit environmental factors as partial constituents of addiction, we can expect the status of addiction likewise to vary along with the strength and prevalence of those external factors.

Much of the attraction of the classical Disease Model lies in its rhetorical force in destigmatising addiction; it replaced a standard view of addiction as a form of moral failure ([10], p. 1552) and emphasised the degree to which addicts lacked control over their actions. While that emphasis always had a strong element of rhetorical overstatement addicts are clearly in more control of their condition than e.g. cancer patients, while much recent research shows that the majority of addicts "mature out" of their conditions eventually, without intervention [66] an externalist modification of the model provides a more realistic view, while allowing us to acknowledge that the degree to which addiction is controllable is at least substantially dependent on the affordances of the environment, and the scope it allows for the making of choices. And rather than seeing addiction as inherently progressive, tending inexorably towards mortality if untreated, we can see that treatment often just is adjustment of the constitutive environment, which the addict may or may not deliberately seek; in many cases, treatment of extra-neural factors such as the body of the addict, their social life, their home life, their environment etc. will be as important and effective as intervening directly upon deregulated neuromodulatory mechanisms. So, with the Disease Model suitably adjusted in light of $4 \mathrm{E}$ insights about the nature of disease, the conflict with the Choice Model largely dissolves; it is now apparent that the dichotomy between them was a false one all along. The two do not define outer limits of a continuum, between which all other views must be located; each point of difference between them has, in truth, been illusory.

Of course, there is only so much that can be gleaned from discussing caricatures; it will be helpful to consider how this shift in perspective might apply to a real-life dispute from the literature. Consider an important recent exchange between Gabriel Segal and Nick Heather. Segal [44] defends the claim that alcoholism is a disease, albeit in a heterodox way. As Heather ([111], p. 321) writes, "(h)e strips away from the disease concept almost all the features that have previously been seen as essential to it," including the requirements "that problem drinking is chronic, irreversible, or progressive", that alcoholics are "physically dependent on alcohol", that they cannot "recover without treatment or a recovery program," and that they are not "morally responsible for their drinking and its consequences". In short, Segal's account of "disease" is right in line with the "Disease Model 2.0" suggested above, save that "in Segal's account... alcoholism is all-or-none; although among those having the disease it comes in degrees, you either have alcoholism or you do not" ([111], p. 322).

"Most surprisingly," for Heather ([111], p. 321.), and again in line with the revised model, Segal characterises alcoholism as "a psychological disease" rather than a brain disease ([44], p. 301-2). Heather's surprise is due to Segal's support for the incentive sensitization theory of addiction although, as we argue in the next section, this too fits neatly into the externalist perspective. Heather himself, while a prominent critic of the disease view, is no straightforward supporter of the Choice Model, and is known for his emphasis on the compulsive aspect of addiction (e.g. [67,68]). His opposition to the "disease" label is in the end pragmatic, for while he grants that "calling a category of behavior a disease is essentially arbitrary; however, it has important consequences"

\footnotetext{
${ }^{6}$ Even Boorse, perhaps the only major figure who still eschews any role for evaluative criteria in defining disease, views it as sufficiently large deviation from a "statistically normal range of function", where that range is to be contextually defined.
}

([111], p. 323). In particular, he argues, the rhetoric and assumptions that accompany viewing addiction as a disease obscure the importance of viewing it as a public health issue; he quotes psychiatrist Robert Kendell [69] to the effect that "alcohol-related harm is more a political than a medical problem" ([111], p. 323).

But for an externalist, there is no tension here. Disease, dysfunction, and illness, properly understood, are often crucially and constitutively dependent on the arrangement of the material, social, and politico-legal environment, among numerous other external institutions and resources that may be encompassed by and implicated in our healthy or pathological cognitive processes. It is just for this reason that the "disease, but not brain disease" distinction made by Segal is important.

Indeed, the distance between the two collapses further when we consider the exchange between Heather and Ole-Jørgen Skog, to which Heather alludes in his contribution to this volume. Responding to Heather's definition of addiction in terms of "repeated failures to refrain from drug use despite prior resolutions to do so" ([70], p. 3), Skog objects that we should still regard as an addict somebody who has never actually tried to give up drug use, but would counterfactually suffer repeated failures were they to do so; actual failure may be an important diagnostic criterion, but the user - "the same person in two different contexts" - is in the same neurological state either way ([71], p. 160). Heather's response is on the one hand epistemic - Skog's view would mean that until repeated failure manifests, we are not in a position to say whether someone is addicted or not - and on the other metaphysical; Skog, he argues, confuses the neuro-adaptation both users possess in common with the behavioural phenomenon of addiction, which consists in the interaction of that neuro-adapted brain-state with a suitable environmental setting ([72], p. 177). Music to an externalist's ears!

\section{The world of the addict}

A central concept in the literature on enactive and embodied cognition is that of affordance. Though the concept borrows heavily from the work of Maurice Merleau-Ponty (esp. [73]), contemporary use of the term originates with the work of J.J. Gibson, who defined the affordances of a given environment, for a given animal, as "what it offers the animal, what it provides or furnishes, either for good or ill... (the term) implies the complementarity of the animal and the environment" [74]. The features of the environment - objects, arrangements, processes "suggest" to the concerned observer how they may be acted upon or interacted with. In this way, we as agents experience the environment as "facilitating", even encouraging or inviting [75], our action. It seems to us to be suffused with potential, relative to our priorities.

Externalist psychiatry points to breakdown or disruption in the environment's affordances as the grounds of at least some mental illness; the disorder may consist in the environment failing to make itself available to the patient in important ways. Depression seems to involve a general loss of affordance; the world ceases to seem to "offer itself" to be acted in and upon according to our priorities and values. Those values thus in a sense lose their valency; they no longer perceptually solicit the depressed person's engagement, and she can no longer motivate herself to act on them. The world strikes her as "flat" and "colourless", no longer welcoming or hospitable to her as an agent [9].

Similarly, we have elsewhere argued that Autistic Spectrum Disorder may in large part be constituted by an inability to experience the normal affordances of the human social world; patients are unable to discern, to access, and to act in accordance with the "mental institutions" which structure neurotypical social interaction [13,34]. In a famous image, $\mathrm{H}$. L.A. Hart poses Wittgenstein's classic "rule-following" problem in terms of a father instructing his child about proper behaviour upon entering a church ([76], ch. 7; [77], $\S \S 185-243$; [78]); he takes off his hat and says "this is what you are supposed to do". It's not specified to the child whether or not he must use one hand rather than the other to do so, whether he must do so on all days of the week, or just on Sundays, or just before midday, that hats and caps, but not e.g. wigs are to be included... 
but the child can work all of this out, effortlessly, by access to the mental institutions which determine, and indicate, and are constituted by what people typically care about in this sort of scenario. This is a form of "vehicle externalism", meaning that the mental processes we are concerned with are realised in part by a resource external to the brain, but the external vehicle in question is not just a concrete artefact; it's a set of conventions, practices, mutual understandings, and so forth.

Now, does addiction look like a disruption of affordances in this fashion? Here's the testimony of a recovering addict, the philosopher Peg O'Connor:

In many ways, I think active alcoholics have a form of life different from that of recovered alcoholics, as well as from that of non-alcoholics. The world we all share is the same in important respects. But in some deep ways, the lived world and its meanings are radically different. Consider some differences between people with long-term sobriety and those who are actively alcoholic, or even newly entering a recovery program. An unrecovered alcoholic often can't even understand the alcoholic who says, "Your life will be better without alcohol. You will like yourself more. You will have more friends and a lot more fun." To the unrecovered, people in recovery can seem preachy and sanctimonious. Early on, no matter how many times and in how many ways a long-timer says this, what the unrecovered person hears is more like, "Blah, blah, serenity. Blah, blah, blah, serenity," as a great Gary Larson cartoon reminds us. Non-alcoholics can't fathom alcoholics, those of us who would risk our livelihoods, families, and whatever else we hold near and dear in order to drink. We can offer huge chains of reasoning that make sense to us, and to other alcoholics. But to non-alcoholics, unless they've been enlisted in enabling us, we can seem to be beyond logic and sanity. [79]

It is instructive to consider this passage in light of the seminal theory of addiction as incentive-sensitization or incentive-salience (e.g. [40, 80-84]). This holds that, by enhancing mesotelencephalic dopamine neurotransmission, addictive drugs effectively hijack that neural system's characteristic psychological function of incentivising the brain to seek reward-associated stimuli. The drugs' effect is to hypersensitize the dopamine reward system to such drugs and thereby to trigger pathological incentive motivation ("craving"), which persists even after long periods of abstinence. ${ }^{7}$

In lay terms: drugs affect the mechanisms that make our appetites responsive to particular triggers, so that our appetites for drugs become completely disproportionate to the amount of pleasure actually gained from them. Drugs thereby come to be wanted by the addict, far more than they are actually liked; their "salience" as incentives to action is radically amplified. In this way, the experience of drug-taking not only alters the brain chemistry, but via the brain chemistry it profoundly changes the drug-taker's motivational space, the agential structure of her environment.

To undergo this process, in other words, is literally to have one's world changed; the world itself does not change, but the addict's world the world of their lived experience, or Lebenswelt [85] - is radically altered. Indeed, the process represents an epistemically transformative experience [86,87]; the lived worlds of the addict and the sober person, with their characteristic motivations and affordances, become as O'Connor describes ([79]; O'Connor cites [77] $\S 19, \S 23, \S 241$ ), mutually incomprehensible, and mutually epistemically inaccessible.

The externalist perspective thus allows us to integrate the leading

\footnotetext{
${ }^{7}$ Since the incentive-salience theory is often seen as a key plank of the braindisease view of addiction, and is fundamentally concerned with neural processes, a reader might worry that it does not sit particularly easily with the $4 \mathrm{E}$ perspective we advance here. We think this is unproblematic, as we emphasise the complementary nature of $e . g$. the affordance literature and the neurological literature in the example given above. But for more detailed views of how incentive-salience can be seen as part of an inherently embodied learning process, see $[10,12]$.
}

neurochemical account of addiction with typical first-hand accounts of the phenomenology, or lived experience, of the addict. And further support is lent to this integration by similar work applying the incentivesensitization theory to Obsessive-Compulsive Disorder [88,89]. OCD, which presents a remarkably similar phenomenological cocktail of compulsion, freewill, and responsibility, is equally naturally understood as being constituted by a derangement of environmental affordances; that it seems to result from a similar derangement of the feedback relation between the environment and the brain's reward system can scarcely be an accident.

\section{Recovery and cognitive scaffolding}

Closely related to the idea of environmental affordances is that of cognitive scaffolding. That is, our cognitive activity is frequently scaffolded by external resources; we arrange our environment to facilitate our mental processes, by replacing the cognitive tasks and challenges that typically face us with more tractable ones. This is a key part of the view of cognition as being embedded in, and extended over, the material and informational environment, and its powers as being supported and enhanced by the suitable configuration of that environment.

Sometimes these are homely and familiar; one of us, as an inveterate forgetter-of-packed-lunches, finds that leaving his rucksack beside the refrigerator overnight makes him much more likely to remember to retrieve the sandwiches he has left there, before departing for work in the morning. But the literature on embedded and extended cognition envisions much more radical and ambitious instances. In a landmark text in cognitive science, for instance, Lakoff and Johnson [90] argued that patterns of human cognition and behaviour were strongly dependent on a deep and ubiquitous set of associations scaffolded in the main by familiar linguistic metaphors. Edwin Hutchins [91] has demonstrated that cognitive processes take place not merely at the level of individual human brains, but across systems - Naval ships, for instance - composed often of numerous human agents, and a great deal of artefactual apparatus. Perhaps most radically, Andy Clark and David Chalmers [29] have argued that external objects can function as part of the mind if they perform the same role in supporting cognitive processes as might otherwise be performed by parts of the brain. In a famous thought-experiment, they consider Otto and Inga, both of whom are simultaneously travelling to a museum; while Inga navigates her way there from memory, Otto - who has Alzheimer's disease - relies on written directions in a notebook. Since the only difference between the two cases is that the process of navigation takes place wholly inside the brain in Inga's case and partly outside it in Otto's, they argue, it is only arbitrarily and dogmatically that we can insist on confining "cognition" to what occurs within the confines of the skull. For the psychiatric externalist, cognitive and other mental disorders can therefore be constituted by disturbances to, or absences of, such external resources.

This insight, we suggest, helps to understand much of what is observed in recovery from addiction, and the many strategies and resources that are employed to support it. In some cases, these may be quite simple tokens - consider the chips and key fobs given to Alcoholics Anonymous members to mark and celebrate milestones in sobriety, which are often invaluable in helping addicts to steel their resolve to persevere - while in others they may be very complicated, multifaceted strategies. But in either case they are easily, and illuminatingly, construed as "scaffolds"; (re)arrangements of the material and informational environment which alter the cognitive tasks and challenges it presents us with. Indeed, one way that they may do so is by altering the environment's emotional valence and significance [92]; by creating new affordances or strengthening existing ones. That is, since our affective processes may admit of externalist analysis just as much as our cognitive ones, affective scaffolding may be just as important as cognitive scaffolding in supporting recovery.

A recent line of philosophical analysis of addiction, developed by Chandra Sripada [93], explains just why this sort of scaffolding may be 
so significant. Humans, he observes, are fundamentally fallible; this has been a theme in philosophical writing on the human condition going back at least to St. Augustine [94]. Even when we are extremely good world-class - at tasks, we will fail at them; Steph Curry, the most accurate free throw-taker in professional basketball history, misses about one such shot in every ten. The resisting of one's cravings is a highly complex, difficult, cognitive task; one requiring near-constant vigilance in the face of countless temptations and reminders. The IRA are reported to have told UK prime minister Margaret Thatcher, following a failed assassination attempt, that "we only need to be lucky once; you need to be lucky every time". If even Homer nods, we can scarcely wonder that so many addicts do eventually relapse, given the sheer number of separate occasions on which they must succeed in resisting their cravings, minute by minute, hour by hour, day by day, if they are to remain sober.

So a huge amount of what goes into successful recovery from addiction, and what is involved in effective therapeutic intervention, seems to consist of strategies and resources to simplify the task of resisting cravings; to make it more tractable; to guard against such failures, and to manage the consequences when they begin to happen. Recovering addicts invariably display "self-binding" practices [95], on the model of Odysseus binding himself to the ship's mast in order to resist the sirens' song: finding new social circles, and routes to and from work unassociated with their prior drug use; sending paycheques to spouses' accounts to prevent themselves from gambling; wearing long-sleeved shirts to avoid constantly seeing inviting and available veins; removing cigarette-lighters from their cars ([96], p. 21). ${ }^{8}$ Moreover, as Hanna Pickard [97] observes, addiction often conveys a sense of self and self-worth. In other words, it need not exclusively be experienced as a diminishment or loss of self (i.e., destruction of an individual's life due to addictive cravings or impulses) but rather as an identity gain [98]: a pathway to meaningful practices, relationships (e.g., with fellow addicts), social roles, and other forms of group identification that enduringly scaffold an individual's identity and sense of purpose. Accordingly, recovery may, among other things, involve cultivating environments and networks of relationships that scaffold the development and maintenance of post-addiction sources of social reward and relationships, self-esteem, and social identity. As one addict in recovery says, a non-addict sense of self does not suddenly emerge once the addiction is overcome; it must be actively imagined and created: "[Y] ou've got to work at becoming someone and something else" (quoted in [97], p.15). Supportive material and social niches furnish scaffolding essential for this post-addiction identity-work.

These insights may - and indeed, already do - help us to design better programmes of therapy, by focussing on identifying, isolating, and altering the cognitive tasks the addict must perform in order to maintain sobriety, with a view to maximising her chances of successfully repeated performance. By constructing a material and social niche that is free from salient reminders of addiction, for example - an environment that resists the formation of bad habits and poor choices, by making it more difficult for the addict to encounter the people and places that are most likely to prompt addictive behaviour and scaffold her social identity as an addict - the agent can improve these chances: not by altering her brain chemistry or otherwise resolving the internal determinants of her condition, but by transforming her experienced relation to the world around her and manipulating the nudges, encouragements, and deterrences the people and things in this world afford. More positively, too, recognising addiction as a dysregulation of the wider agentenvironment dynamics may allow us to identify new aspects of that

\footnotetext{
${ }^{8}$ Just as, in Alva Noë's [110] words, "the so-called highjacking of the reward system is not itself a neurochemical process (but) a process whereby neurochemical events get entrained within ... a larger pattern of action and decision making," so we can see that the process of recovery involves a similarly widely-embedded process of entrainment.
}

dynamic to address. For instance, if an overly narrow field of reward possibilities fuels progressively extreme sampling of a few rewards ([99], p. 115ff.), then working to create an environment with wider reward possibilities (new hobbies, serving the community, new friends, etc.) could be especially beneficial to staving off addiction. ${ }^{9}$

\section{Conclusion}

We began by observing the unusually complex, many-layered character of the psychiatric phenomenon of addiction, salient facets of which appear to arise at different levels of explanation: the level of brain structures and their chemistry; the level of individual persons and their choices; the level of legal, social, and political institutions; and so forth. We have offered some preliminary foundations for an integrative theoretical framework whose aim is to capture several of these levels in a conceptually coherent way, and to shed new light on addiction by reformulating some entrenched disputes from extant literature on the topic. The Externalist or $4 E$ framework encourages us to recognise that a person's mental health or disorder, like all of her other psychological attributes, depends heavily upon how she is situated within a richlyscaffolded material and interpersonal environment. Facts that concern what goes on outside a person's head help to determine her status as mentally healthy or ill, and may even partially constitute the material underpinnings of her psychiatric condition.

In the case of addiction, we have argued, the externalist perspective can help to dissolve the conflict between the models of Choice and Disease, by reconceiving disease as something that is realised only when a wide profile of neural, bodily, and external-environmental conditions is met. By building the social, the cultural, and the material into our picture of disease - and widening our focus beyond the brain - the gap between addiction-as-disease and addiction-as-choice is reduced, perhaps to the point of elimination. Secondly, the externalist's emphasis of the cognitive agent's powers to make meaning for herself by manipulating significant parts of the surrounding environment - and thereby manipulating the dynamic interaction of brain chemistry, interoception, and material and informational environment - enables us to reconsider the symptoms of addiction, and the addict's strategies for recovery. Addictive behaviours do not occur in a vacuum: they are drawn out of the agent in particular contexts; perceptually invited in some scenarios and disinvited in others. The familiar terrain in which a person's addiction has become established and habituated is likely to afford few salient obstacles to, say, continued drug or alcohol abuse. By attending to and altering her surroundings, however - for instance through the use of physical tokens of success; through interaction with sources of emotional support; or by mapping goals and milestones in a tangible format - it is possible for the addict to let the outside world take on some of the psychological labour of recovery.

\section{References}

[1] R.B. Brandom, Between Saying and Doing: Towards an Analytic Pragmatism, Oxford University Press, Oxford, 2008.

[2] R. Cooper, Where's the problem? Considering Laing and Esterson's account of schizophrenia, social models of disability, and extended mental disorder, Theor. Med. Bioeth. 38 (4) (2017) 295-305.

[3] W. Davies, Externalist psychiatry, Analysis 76 (3) (2016) 290-296.

[4] S.E. De Haan, Enactive Psychiatry, Cambridge University Press, Cambridge, 2020.

[5] Z. Drayson, Embodied cognitive science and its implications for psychopathology, Philos. Psychiatry Psychol. 16 (4) (2009) 329-340.

[6] S.N. Glackin, Individualism and the medical: what about somatic externalism? Analysis 77 (2) (2017) 287-293.

[7] G.A. Hoffman, Out of our skulls: how the extended mind thesis can extend psychiatry, Philos. Psychol. 29 (8) (2016) 1160-1174.

[8] J. Krueger, Schizophrenia and the scaffolded self, Topoi 39 (2020) 597-609.

\footnotetext{
${ }^{9}$ We thank an anonymous reviewer for pointing out this possibility, as well as its resonances with the lessons of the "Rat Park" experiments.
} 
[9] J. Krueger, G. Colombetti, Affective affordances and psychopathology, Discipline Filosofiche 18 (2) (2018) 221-247. Special Issue: "Philosophical Perspectives on Affectivity and Psychopathology,".

[10] M. Lewis, Brain change in addiction as learning, not disease, N. Engl. J. Med. 379 (16) (2018) 1551-1560.

[11] M. Merritt, Instituting impairment: extended cognition and the construction of female sexual dysfunction, Cogn. Syst. Res. 25-26 (2013) 47-53.

[12] M. Miller, J. Kiverstein, E. Rietveld, Embodying addiction: a predictive processing account, Brain Cogn. 138 (2020) 105495.

[13] T. Roberts, J. Krueger, S.N. Glackin, psychiatry beyond the brain: externalism, mental health, and autistic spectrum disorder, Philos. Psychiatry Psychol. 26 (3) (2019) E-51-E-68.

[14] A. Sneddon, Towards externalist psychopathology, Philos. Psychol. 15 (3) (2002) 297. -216 .

[15] M. Sprevak, Neural sufficiency, reductionism, and cognitive neuropsychiatry, Philos. Psychiatry Psychol. 18 (4) (2011) 339-344.

[16] M. Maiese, Embodied Selves and Divided Minds, University Press, Oxford, 2016.

[17] T. Fuchs, Ecology of the Brain: The Phenomenology and Biology of the Embodied Mind, Oxford University Press, Oxford, 2018.

[18] C.M. Strickland, C.J. Patrick, Biomedical model, in: R.L. Cautin, S.O. Lilienfeld (Eds.), The Encyclopedia of Clinical Psychology, vol. I, Wiley-Blackwell, Oxford, 2015.

[19] G.L. Engel, The need for a new medical model: a challenge for biomedicine, Science 196 (1977) 129-136.

[20] N.C. Andreasen, The Broken Brain: The Biological Revolution in Psychiatry, Harper \& Row, New York, 1985.

[21] I. Gold, Reduction in psychiatry, Can. J. Psychiatry 54 (2009) 506-512.

[22] A.F. Schatzberg, Presidential address, Am. J. Psychiatry 167 (2010) 1162-1165.

[23] B.J. Deacon, The biomedical model of mental disorder: a critical analysis of its validity, utility, and effects on psychotherapy research, Clin. Psychol. Rev. 33 (7) (2013) 846-861.

[24] T. Szasz, The myth of mental illness, Am. Psychol. 15 (1960) 113-118.

[25] T. Szasz, Pharmacracy: Medicine and Politics in America, Praeger, Westport, CT, 2001.

[26] C. Boorse, On the distinction between disease and illness, Philos. Public Aff. 5 (1975) 49-68.

[27] C. Boorse, Health as a theoretical concept, Philos. Sci. 44 (1977) 542-573.

[28] G. Dickie, What is art? An institutional analysis, in: G. Dickie (Ed.), Art and the Aesthetic: An Institutional Analysis, Cornell University Press, Ithaca, NY, 1974.

[29] A. Clark, D.J. Chalmers, The extended mind, Analysis 58 (1) (1998) 7-19.

[30] M. Maiese, An enactivist approach to treating depression: cultivating online intelligence through dance and music, Phenomenol. Cogn. Sci. 19 (3) (2020) 523-547.

[31] T. Fuchs, Depression, intercorporeality, and interaffectivity, J. Conscious. Stud. 20 (7-8) (2013) 219-238.

[32] M. Ratcliffe, Experiences of Depression: A Study in Phenomenology, University Press, Oxford, 2015.

[33] H. De Jaegher, Embodiment and sense-making in autism, Front. Integr. Neurosci. 7 (15) (2013) 1-19.

[34] J. Krueger, M. Maiese, Mental institutions, habits of mind, and an extended approach to autism, Thaumzein 6 (2018) 10-41.

[35] J. van Grunsven, Perceiving 'Other' minds: autism, 4E cognition, and the idea of Neurodiversity, J. Conscious. Stud. 27 (7-8) (2020) 115-143.

[36] J. Krueger, L. Osler, Engineering affect: emotion regulation and the techno-social niche, Philos. Top. 47 (2) (2019) 1-53.

[37] N. Hanprathet, M. Manwong, J. Khumsri, R. Yingyeun, M. Phanasathit, Facebook addiction and its relationship with mental health among thai high school students, J. Med. Assoc. Thai. 98 (2015) S81-S90.

[38] Krueger, J., \& Osler, L. (Forthcoming). Agency, Environmental Scaffolding, and the Development of Eating Disorders - Commentary on Rodemeyer, C. Tewes \& G. Stanghellini, Time and Body: Phenomenological and Psychopathological Approaches. Cambridge: Cambridge University Press.

[39] P. Wang, X. Wang, Y. Wu, X. Xie, X. Wang, F. Zhao, M. Ouyang, L. Lei, Social networking sites addiction and adolescent depression: a moderated mediation model of rumination and self-esteem, Pers. Individ. Dif. 127 (2018) 162-167.

[40] R. Holton, K. Berridge, Addiction between compulsion and choice, in: N. Levy (Ed.), Addiction and Self-Control, Oxford University Press, Oxford, 2013, pp. 239-268.

[41] H. Pickard, S.H. Ahmed, B. Foddy, Alternative models of addiction, Front. Psychiatry 6 (2015) 5-6.

[42] E.M. Jellinek, Alcoholism: a genus and some of its species, Can. Med. Assoc. J. 24 (1960) 1341-1345.

[43] A.I. Leshner, Addiction is a brain disease, and it matters, Science 278 (1997) 45-47, 3rd October 1997.

[44] G. Segal, Alcoholism, disease, and insanity, Philos. Psychiatry Psychol. 20 (2013) $297-315$.

[45] N.D. Volkow, Drugs, Brains and Behavior: The Science of Addiction, National Institute of Drug Abuse NIH Pub 10-5607, National Institutes of Health, Bethesda, MD, 2010.

[46] N.D. Volkow, G.F. Koob, A.T. McLellan, Neurobiologic advances from the brain disease model of addiction, N. Engl. J. Med. 374 (2016) 363-371.

[47] G.S. Becker, K.M. Murphy, A theory of rational addiction, J. Polit. Econ. 96 (1988) 675-700.

[48] B. Foddy, J. Savulescu, Addiction is not an affliction: addictive desires are merely pleasure-oriented desires, Am. J. Bioeth. 7 (2007) 29-32.
[49] N. Heather, I. Robertson, Problem Drinking, Oxford University Press, Oxford, 1997.

[50] G.M. Heyman, Addiction: A Disorder of Choice, Harvard University Press, Cambridge, MA, 2009.

[51] B.K. Alexander, B.L. Beyerstein, P.F. Hadaway, R.B. Coambs, Effect of early and later colony housing on oral ingestion of morphine in rats, Pharmacol. Biochem. Behav. 15 (1981) 571. -57.

[52] B.K. Alexander, The Globalization of Addiction: A Study in the Poverty of the Spirit, Oxford University Press, Oxford, 2008.

[53] S.H. Ahmed, Validation crisis in animal models of drug addiction: beyond nondisordered drug use toward drug addiction, Neuroscience Biobehavioral Review 35 (2010) 172-184.

[54] G. Zernig, K.K. Kummer, J.M. Prast, Dyadic social interaction as an alternative reward to cocaine, Front. Psychiatry 4 (2013) 100.

[55] G. Ainslie, A research-based theory of addictive motivation, Law Philos. 19 (2000) 77-115.

[56] N. Levy, Addiction, responsibility, and ego depletion, in: J. Poland, G. Graham (Eds.), Addiction and Responsibility, MIT Press, Cambridge MA, 2011, pp. 89-111.

[57] L.N. Robins, Vietnam veterans' rapid recovery from heroin addiction: a fluke or normal expectation? Addiction 88 (1993) 1041-1954.

[58] N. Levy, Addiction is not a brain disease (and it matters), Front. Psychiatry 4 (2013) 24.

[59] S.N. Glackin, Philosophical issues in the addictions, in: S.Y. Sussman (Ed.), The Cambridge Handbook of Substance and Behavioral Addictions, Cambridge University Press, Cambridge, 2020, pp. 38-50.

[60] K.W.M. Fulford, Moral Theory and Medical Practice, Cambridge University Press, Cambridge, 1989.

[61] L. Nordenfelt, Functions and health: towards a praxis-oriented concept of health, Biol. Theory 13 (2018) 10-16.

[62] I. Pörn, Health and adaptedness, Theor. Med. 14 (1993) 295-304.

[63] S. Werkhoven, A dispositional theory of health, Br. J. Philos. Sci. 70 (2019) 927-952.

[64] J.C. Wakefield, The concept of mental disorder: on the boundary between biological facts and social values, Am. Psychol. 47 (1992) 373-388.

[65] J.C. Wakefield, Disorder as harmful dysfunction: a conceptual critique of DSM-IIIR's definition of mental disorder, Psychol. Rev. 99 (1992) 232-247.

[66] Hanna Pickard, The purpose in chronic addiction, AJOB Neurosci. 3 (2012) 40-49.

[67] N. Heather, Is the concept of compulsion useful in the explanation or description of addictive behaviour and experience? Addict. Behav. Rep. 6 (2017) 15-38.

[68] N. Heather, G. Segal, Understanding addiction: Donald Davidson and the problem of Akrasia, Addict. Res. Theory 21 (2013) 445-452.

[69] R.E. Kendell, Alcoholism: a medical or a political problem? Br. Med. J. 283 (1979) 367-371.

[70] N. Heather, A conceptual framework for explaining drug addiction, J. Psychopharmacol. 12 (1998) 3-7.

[71] O.-J. Skog, Addiction: definitions and mechanisms, in: R.E. Vuchinich, N. Heather (Eds.), Choice, Behavioural Economics and Addiction, Elsevier, Kiddington, Oxford, 2003, pp. 157-175.

[72] N. Heather, Comments on Skog, in: R.E. Vuchinich, N. Heather (Eds.), Choice, Behavioural Economics and Addiction, Elsevier, Kiddington, Oxford, UK, 2003, pp. 176-181.

[73] M. Merleau-Ponty, Phenomenology of Perception, Routledge and Kegan Paul, London, 1962.

[74] J.J. Gibson, The Ecological Approach to Visual Perception, Houghton Mifflin, Boston, 1979.

[75] K. Koffka, Principles of Gestalt Psychology, Lund Humphries, London, 1935.

[76] H.L.A. Hart, The Concept of Law, Clarendon Press, Oxford, 1961.

[77] L. Wittgenstein, Philosophical investigations, in: G.E.M. Anscombe, R. Rhees (Eds.), G.E.M. Anscombe (Trans.), Blackwell, Oxford, 1953.

[78] L. Wittgenstein, On certainty, in: G.E.M. Anscombe, G.H. von Wright (Eds.), G.E. M. Anscombe \& D. Paul (Trans.), Blackwell, Oxford, 1969.

[79] T. Morris, Interview With a Philosopher: Aristotle and Wittgenstein Walk Into a Bar - Philosophy and Addiction, Huffington Post. 10/12/2011. URL =, 2011, https ://www.huffingtonpost.com/tom-morris/philosophy-and-addiction_b_999933. html.

[80] K.C. Berridge, T.E. Robinson, Drug addiction as incentive sensitization, in: J. Poland, G. Graham (Eds.), Addiction and Responsibility, MIT Press, Cambridge, MA, 2011, pp. 21-54.

[81] K.C. Berridge, T.E. Robinson, Liking, wanting, and the incentive-sensitization theory of addiction, Am. Psychol. 71 (2016) 670-679.

[82] S.E. Hyman, Addiction: a disease of learning and memory, Am. J. Psychiatry 162 (2005) 1414-1422.

[83] T.E. Robinson, K.C. Berridge, The neural basis of drug craving: an incentivesensitization theory of addiction, Brain Res. Rev. 18 (1993) 247-291.

[84] T.E. Robinson, K.C. Berridge, The Incentive Sensitization Theory of Addiction: Some Current Issues, Philos. Trans. Biol. Sci. (2008) 363.

[85] E. Husserl, The Crisis of European Sciences and Transcendental Phenomenology: An Introduction to Phenomenological Philosophy, D. Carr (trans.), Northwestern University Press, Evanston, 1970.

[86] L.A. Paul, Transformative Experience, Oxford University Press, Oxford, 2014.

[87] L.A. Paul, What you can't expect when you've expecting, Res Philos. 92 (2015) $149-170$. 
[88] S.E. De Haan, E. Rietveld, M. Stokhof, D. Denys, The phenomenology of deep brain stimulation-induced changes in OCD: an enactive affordance-based model, Front. Hum. Neurosci. 7 (2013) 1-14.

[89] S.E. De Haan, E. Rietveld, M. Stokhof, D. Denys, Becoming more oneself? Changes in personality following DBS treatment for psychiatric disorders: experiences of OCD patients and general considerations, PLoS One 12 (2017), e0175748.

[90] G. Lakoff, M. Johnson, Metaphors We Live By, University of Chicago Press, Chicago, 1980.

[91] E. Hutchins, Cognition in the Wild, MIT Press, Cambridge MA, 1995.

[92] G. Colombetti, T. Roberts, Extending the extended mind: the case for extended affectivity, Philos. Stud. 172 (5) (2015) 1243-1263.

[93] C. Sripada, Addiction and fallibility, J. Philos. 115 (2018) 569-587.

[94] E. Bruenig, It Will Happen Again and Again, URL = <https://medium.com/@ ebruenig/it-will-happen-again-and-again-bb375372cd13>, 2018.

[95] T. Schelling, The intimate contest for self-command, Public Interest 60 (1980) 94-118.

[96] S. Satel, S.O. Lilienfeld, Addiction and the brain-disease fallacy, Front. Psychiatry 4 (141) (2013) 17-27.

[97] H. Pickard, Addiction and the self, Noûs (2020) 1-25, https://doi.org/10.1111/ nous.12328, 2020.

[98] G.A. Dingle, T. Cruwys, D. Frings, Social Identities as Pathways into and out of Addiction, Front. Psychol. 6 (1795) (2015) 1-12.

[99] P. Sterling, What Is Health? Allostasis and the Evolution of Human Design, MIT Press, Cambridge MA, 2020.

[101] S.E. De Haan, An enactive approach to psychiatry, Philos. Psychiatry Psychol. 27 (1) (2020) 3-25.
[102] S.N. Glackin, Grounded disease: constructing the social from the biological in medicine, Philos. Q. 69 (275) (2019) 258-276.

[103] E. Castrén, Is mood chemistry? Nat. Rev. Neurosci. 6 (3) (2005) 241-246.

[104] W.C. Drevets, J.L. Price, M.L. Furey, Brain structural and functional abnormalities in mood disorders: implications for neurocircuitry models of depression, Brain Struct. Funct. 213 (1-2) (2008) 93-118.

[105] M. Pandya, M. Altinay, D.A. Malone Jr., A. Anand, Where in the brain is depression? Curr. Psychiatry Rep. 14 (6) (2012) 634-642.

[106] M. Wehrenberg, S. Prinz, The Anxious Brain: The Neurobiological Basis of Anxiety Disorders and How to Effectively Treat Them, WW Norton \& Company, New York, 2007.

[107] T.R. Insel, R. Quirion, Psychiatry as a clinical neuroscience discipline, Jama J. Am. Med. Assoc. 294 (17) (2005) 2221-2224.

[108] J. Dewey, The unity of the human being, in: J.A. Boydston (Ed.), Later Works of John Dewey, vol. 13, Southern Illinois University Press, Carbondale, 1937/1991, pp. 323-337.

[109] S. Gallagher, Enactivism, causality, and therapy, Philos. Psychiatry Psychol. 27 (2020) 27-28.

[110] A. Noë, Addiction Is Not A Disease Of The Brain, 13.7, Cosmos \& Culture: Commentary on Science and Society, 2011, 9/9/2011. URL $=<$ https://www.npr. org/sections/13.7/2011/09/09/140307282/addiction-is-not-a-disease-of-thebrain? $\mathrm{t}=1595531194302>$.

[111] N. Heather, Is alcohol addiction usefully called a disease? Philos. Psychiatry Psychol. 20 (2013) 321-324. 